\title{
ARQUITETURA PRODUZIDA EM PRESIDENTE PRUDENTE: FORMAÇÃO E DESENVOLVIMENTO DA CIDADE ATÉ A DÉCADA DE 1960
}

\author{
Cristiana Alexandre Pasquini Feltrin Marques \\ Docente do Curso de Arquitetura e Urbanismo da UNOESTE, Presidente Prudente, SP. cristianapasquini@terra.com.br
}

\begin{abstract}
RESUMO
Esta versão pretende abordar os dados históricos de formação e organização do município, bem como apresentar a cidade - contexto do objeto dessa pesquisa. Propõe a Identificação da linguagem arquitetônica da cidade nos anos de formação, bem como a trajetória da produção no período desenvolvimentista. A partir das discussões propostas pelos recortes, o artigo tem como objetivos: em primeiro momento, realizar um mapeamento da cidade, entendendo os processos de transformação urbana até a década de 1960, posteriormente pretende-se levantar a produção arquitetônica inserida nesse período. O método se construirá com análises recorrentes e investigação científica simples e objetiva. Pretenderá se desenvolver, a princípio, por meio de dados sobre a evolução urbana e o desenvolvimento da cidade.
\end{abstract}

Palavras-chave: arquitetura, Presidente Prudente, moderna.

ARCHITECTURE PRODUCED IN PRESIDENTE PRUDENTE: training and development of the city until the 1960s

\section{ABSTRACT}

This version intends to broach the historical data for training and organization of the city, as well as presenting the city - the context object of this research. Proposes the identification of the architectural language of the city in the formative years, as well as the trajectory of the production in developmental period. From the discussions proposed by the graphics, the article has these objectives: The first moment make a survey the city, understanding the process of urban transformation until the 1960s, then intended to know the production architectural inserted in that period. The method is build with analysis applicants and scientific research simple and objective. Will it develop, in principle, using data on urban development and city development.

Keywords: architecture, Presidente Prudente, modern. 


\section{APRESENTAÇÃO DA CIDADE}

A cidade de Presidente Prudente está situada no extremo oeste do Estado de São Paulo. Fundada em 1917, constituiu-se como município em 1921. O município, segundo dados do IBGE de 2009, possui 207.725 habitantes. A cidade é a Capital da Alta Sorocabana e sede da décima Região Administrativa do Estado, formando a Região de Governo de Presidente Prudente.

\section{Estrada de Ferro Sorocabana, Vila Goulart e Vila Marcondes: a Fundação do município de Presidente Prudente}

O desenvolvimento da cultura cafeeira, segundo Abreu (1972), se inicia no Rio de Janeiro e posteriormente se espraia por São Paulo, Minas Gerais e Espírito Santo. Em São Paulo, o Vale do Paraíba é, nesse momento,a primeira área ocupada em grande extensão. Em meados do século XIX o plantio de café começa se expandir para uma nova região: a oeste do Estado. $O$ mercado internacional e a decadência da produção no Vale do Paraíba pelo esgotamento do solo e mão de obra precária levaram o plantio a avançar pelo oeste em busca de terras sadias.

A ocupação dessas terras pela produção do café, segundo Abreu (1972) incentiva a criação de ferrovias no Estado de São Paulo. Os fazendeiros, preocupados com o escoamento da safra, se empenhavam para a implementação das redes ferroviárias. Quanto mais distante dos portos, mais era o incentivo dos produtores, inclusive financeiro. Várias companhias ferroviárias são criadas nesse período, a Paulista, Mogiana, Ituana e a São Paulo Railway.

Porém, a estrada de Ferro Sorocabana, motivo da criação da cidade de Presidente Prudente, não nasce como necessidade de transporte de café. Ela visava inicialmente, segundo Abreu (1972), "ao escoamento de ferro da fábrica São João do Ipanema, para abastecer a capital, o Brasil e os mercados estrangeiros".

O motivo que fez a ferrovia Sorocabana ampliar-se e ligar-se a produção agrícola foi a expansão do plantio de café para oeste do Estado em meados do Séc. XIX.

No ano de 1905, quando a ferrovia Sorocabana passa para as mãos do Governo do Estado, criase a Comissão do Prolongamento e Desenvolvimento da Estrada de Ferro Sorocabana. Segundo Abreu (1972),

A ferrovia foi importante na
economia cafeeira, sendo uma
das vigas de sua infra-
estrutura. Ela significou o
transporte rápido, seguro e
barato para o café, a
comunicação fácil com os
centros grandes. No caso do
extremo oeste de São Paulo,
somam-se outras
circunstâncias: a ferrovia foi a
melhor maneira para os
negociantes de terras levarem
seus compradores em
potencial a conhecerem suas
glebas; favoreceu a a
penetração, os loteamentos, a
ocupação e o aproveitamento
do dolo. Ao longo das
ferrovias, multiplicaram-se os
núcleos urbanos.Permitiu
também o abastecimento
eficiente da rede de
manufaturas inclusive
importadas. Sem a ferrovia,
não teriam entrado tantos
compradores, colonos em
busca de fortunas,
aventureiros de toda espécie.
Ela foi um fator marcante do
progresso na região. E no caso
particular de Presidente
Prudente, o aparecimento e
desenvolvimento da cidade
ligaram-se estreitamente.

Em decorrência do plano de expansão, a Estrada de Ferro Sorocabana cresce de 1906 a 1909 até Salto Grande e atingiu a área denominada Alta Sorocabana em 1916. A estrada chega até Presidente Prudente em 1919 e a cidade já havia se estabelecido desde 1917 com a 


$\begin{aligned} & \text { reunião de dois núcleos } \\ & \text { urbanos criados para }\end{aligned}$
ampararem as vendas de
terras feitas pelo Coronel
Francisco de Paula Goulart e
Coronel Jose Soares
Marcondes que forma os
responsáveis por sua fundação
e sistemática colonização,
respectivamente (Abreu,
1972).

Essas áreas de vendas de terras eram dois imóveis: a fazenda Pirapó-Santo Anastácio, era de propriedade da família do Coronel Goulart. e a fazenda Montalvão, da família do Coronel Marcondes. As duas famílias promoveram, com as vendas de terras, 0 povoamento e 0 aparecimento de Presidente Prudente. Dessa ocupação, nasce a Vila Goulart, um núcleo urbano criado para dar suporte aos compradores de terras da região. Um lugar onde poderia ser o receptor e distribuidor dos produtos vindos pela Estrada de Ferro Sorocabana. À margem direita da linha férrea, paralelamente as terras de Goulart, com características bem distintas, outra colonização: a de Marcondes, Fazenda Moltalvão.

As vendas de terras pelo Coronel Marcondes, em decorrência da estrutura de negócios que oferecia, beneficiou a produção do café e a valorização da lavoura em geral. A empresa vendia pequenas parcelas de terras, feitas por meio de corretores que percorriam o estado, em busca de futuros investidores. Todas as vezes que Marcondes visitava seus negócios em Presidente Prudente, apresentava a região com grande euforia, enfatizando o crescimento e os bons negócios para aqueles que adquirissem terras naquele local. Os dois coronéis trabalhavam com vendas de terras, e, como eram concorrentes, a criação de outro núcleo urbano oposto ao instalado por Goulart, se fez necessário. Uma organização que viesse suprir as necessidades de infraestrutura básica para os compradores de terras que vinham de São Paulo. Foi criada por Marcondes a Vila Marcondes. Os dois povoados cresciam e a busca por terras e negócios fazia com que todos os dias desembarcassem na estação pessoas em busca de oportunidades. Em 1920 o recenseamento, segundo Abreu (1972), atingiu na zona urbana o número de 846 habitantes. Esse desenvolvimento urbano e econômico pede o estatuto político de município.

Antes da criação do município, os dois núcleos urbanos se associam e pedem ao governo do Estado uma proteção: a criação de um Distrito Policial, o que acontece em 1921. O município de Presidente Prudente é criado posteriormente, ainda em 1921, e os coronéis não poderiam ficar de fora das decisões administrativas sobre o município, são eles, então, Goulart e Marcondes que 'brigam' para o cargo de administrador da cidade. Os candidatos Goularistas assumem o poder de 1923-1925 e os Marcondistas de 1926-1930. Acidade vive sob um regime de coronelismo durante toda a década de 1920.

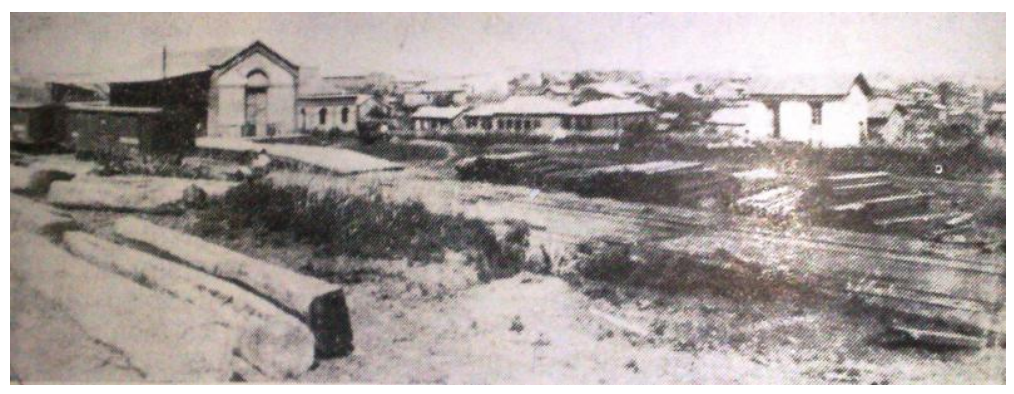

Figura 1. Presidente Prudente em 1921. Fonte: Abreu (1972).

\section{EVOLUÇÃO URBANA E O DISCURSO DESENVOLVIMENTISTA.}

Apesar de a cidade possuir grande potencial, e giro de produtos agrícolas dentro do Estado, o núcleo urbano não recebe investimentos dos setores públicos, Estaduais e Federais. $\mathrm{Na}$ década de 20 , todo incentivo para infra-estrutura vem da iniciativa privada. A construção de edifícios necessários, de madeira ou tijolos, era bancada pelos donos de terras. A cidade permaneceu muito tempo sem melhoras 
urbanísticas, como calçamento, água, esgoto e prédios para os setores públicos. O período datado até 1930, que vive sob a política coronelista, foi marcado como o período mais desprovido, segundo Abreu (1972), da "atenção dos poderes públicos".

A década posterior as administrações coronelistas, apresenta uma característica diferente. As novas administrações aumentam a arrecadação de impostos e proporcionam infraestrutura para a cidade. Uma lei promulgada pela administração do Prefeito Brizolla, Lei 16 de 25 de novembro de 1936, garante a isenção de impostos, com intuito de estimular a construção no quadrilátero central da cidade. A cidade agora tem calçamento, muros, a construção de um Paço Municipal, a construção do Mercado Municipal e as primeiras obras Estaduais. Algumas obras financiadas pelo Governo do Estado: Grupo Escolar, água e esgoto, Prédio para o Fórum, entre outros.

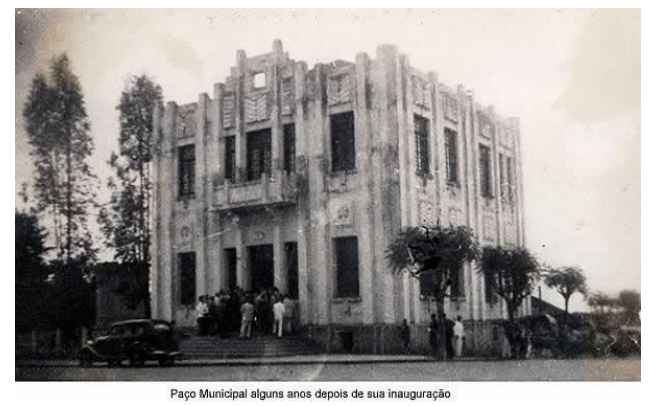

Figura 2. Paço Municipal, meados década 30. Fonte: Abreu (1972).

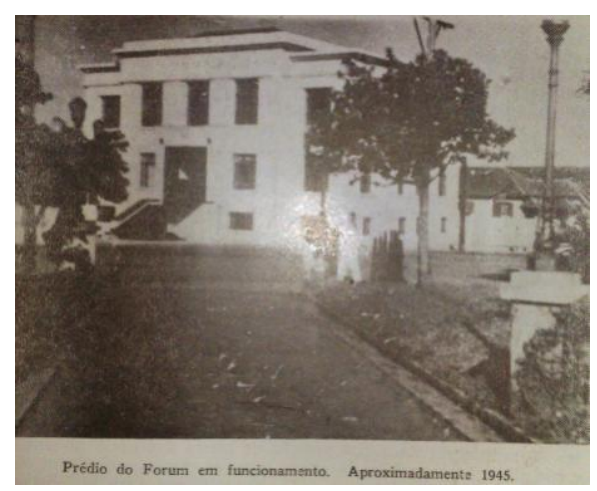

Figura 3. Fórum da cidade em 1945. Fonte: Abreu (1972).
Segundo Sposito, (1983) o final da década de 30 já mostra as características da expansão territorial da cidade, a cidade se estende em direção a Vila Goulart. Esse crescimento se mostra sem planejamento, sem preocupações de regularização e documentos de propriedade e, Segundo Dundes (1998), na década de 30 , a cultura de grãos, motiva a inserção de indústrias na região, algodão, amendoim, mamona, etc. Principalmente o algodão e amendoim tiveram grande importância no processo de urbanização da cidade. Presidente Prudente era 0 centro de comercialização dessa produção.

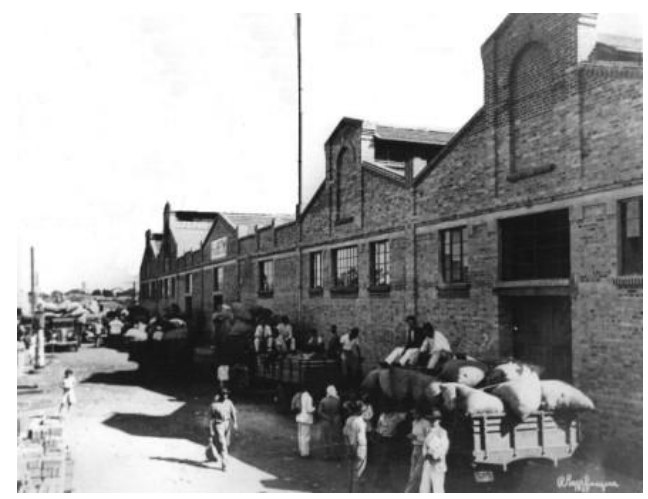

Figura 4. Imagem Indústria Matarazzo beneficiadora de produtos agrícolas em 1937. Fonte: www.culturapp.com.br

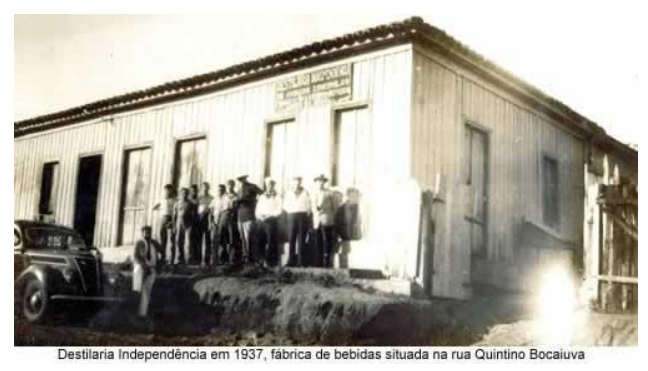

Figura 5. Fábricas domésticas - destilaria em 1937.

Fonte: www.camarapprudente.sp.gov.br

A expansão territorial, apesar da falta de organização, é intensa na década de 30 , mantendo essa característica até a década de 40 e inicio da década de 50 . Porém a 
industrialização da cidade é mais escassa do que no período anterior. Além das grandes indústrias de grãos, a cidade era constituída exclusivamente por pequenas oficinas e fábricas domésticas.

A partir de meados da década de 50, segundo Sposito (1983), a cidade enfrenta um período de desaceleração do crescimento, se comparado com as décadas anteriores. À medida que a produção de grãos se tornava escassa, a atividade agrícola é sobreposta pela pecuária, e as empresas de grande porte deixam a cidade.

Entretanto, na década de 60, um novo ciclo se apresenta para a cidade, e a aproxima do chamado período desenvolvimentista, segundo Dundes (1998),

[...] a partir de 60 estimulado pela conjuntura econômica local e nacional (quando se observa a consolidação do projeto de industrialização pesada no país), um discurso desenvolvimentista que pregava a necessidade do desenvolvimento industrial local para que se atingisse um pleno desenvolvimento (econômico, social e cultural).

As mudanças da economia e o crescente investimento para a industrialização do país, sugere um discurso ideológico industrialista em Presidente Prudente. Segundo Dundes (1998), o crescimento populacional da década de 60, proporciona mudanças nas bases políticas da cidade. Até essa década, Presidente Prudente foi governada por partidos populistas, ligados a política coronelista.

Pôde-se perceber que em fins da década de 60, já se desenrolava a campanha para a substituição dos políticos populistas, alicerçada em crítica que apontavam a incapacidade destes em desenvolver projetos como Plano Diretor da cidade e em viabilizar e implantação do Distrito Industrial proposto pelo governo do Estado.
Desse modo, na década de 70, um novo tipo político, o 'político-empresário', passou a compor 0 quadro diligente local. Nessa transformação solidificou-se um discurso no qual se enfocava a necessidade de promover a industrialização para que o município pudesse alcançar o pleno desenvolvimento econômico, social e cultural. Nele a sociedade urbanoindustrial tornava-se um paradigma a ser atingido (Dundes, 1998).

\section{As novas campanhas eleitorais} apresentavam a ideologia desenvolvimentista como vantagem econômica e apontavam os benefícios para fomentar 0 investimento industrial. Segundo Dundes (1998) essas campanhas usavam as vantagens que a cidade oferecia para a implementação de um pólo industrial: matéria prima, mão de obra barata, vias de transporte, mercado de consumo regional. Em 1965, Presidente Prudente, foi apontada [...] como uma área favorável ao estabelecimento de um Distrito Industrial, que deveria contribuir para a formação de um pólo de desenvolvimento econômico no interior do estado e que estimulasse também [...]

Presidente Prudente é escolhida para receber um distrito industrial planejado, como resposta à proposta Bacia Paraná-Uruguai. Os estudos para a implantação do distrito na cidade vêm do Centro de Pesquisas e Estudos Urbanísticos da Faculdade de Urbanismo e Arquitetura do estado de São Paulo (CPEU). Firma-se então, um convênio entre o município, o CIBPU e CPEU para a elaboração de um projeto. Esse projeto foi entregue em 1968.

Em decorrência desses discursos e propostas desenvolvimentistas, de meados da década de 60, a cidade recebe obras Estaduais, Federais e Municipais, além da iniciativa privada que investe para o crescimento acelerado. As 
campanhas progressistas abrangem as classes altas e a produção da arquitetura que representa o discurso ideológico se instala na cidade.

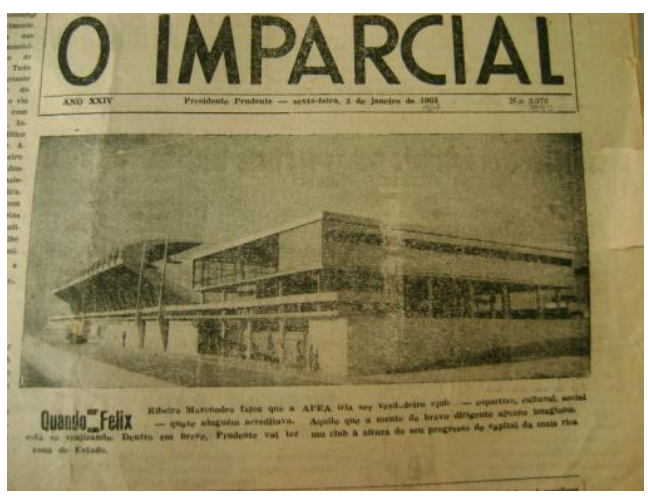

Figura 6. Publicação das Obras do Clube da cidade.

Fonte: Jornal O Imparcial em 03/03/1963.

(Observar a manchete que acompanha: "[...] em breve, Presidente Prudente vai ter o clube à altura do seu progresso [...]").

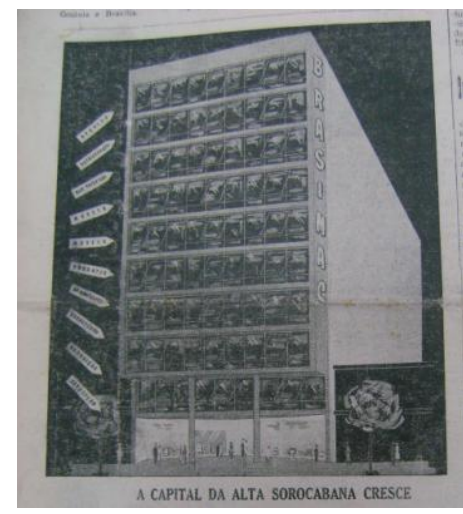

Figura 7. Publicação perspectiva do Prédio Brasimac, 1961.

Fonte: Jornal o Imparcial em 02/04/1961.

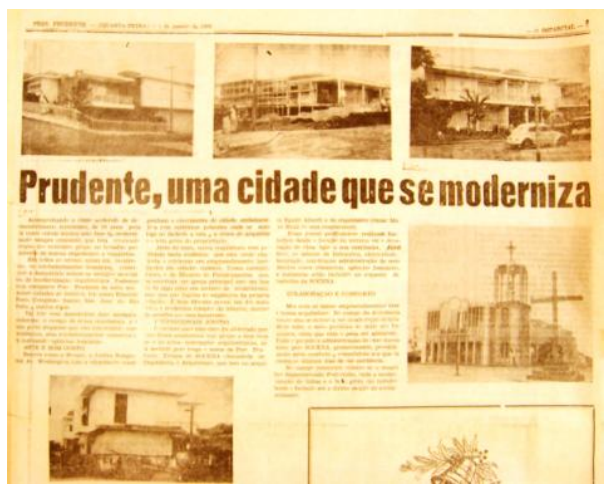

Figura 8. Publicação da produção da arquitetura na cidade, enfatizando o discurso progressista na década de 60 .
Fonte: Jornal O Imparcial em 1/01/1969.

A produção das décadas seguintes demonstra a direção do discurso político. Essa produção é apontada como símbolo de uma 'nova administração' feita, segundo Dundes (1998), por 'políticos empresários' e que em 1996 demonstra um enfraquecimento. A autora sugere que,

aparentemente, as novas
propostas políticas de
desenvolvimento econômico e
social, mas condizentes com a
realidade local, colocaram em
xeque as velhas e inviáveis
propostas de desenvolvimento
industrial."

\section{REFERÊNCIAS}

ABREU, D. S. Formação Histórica de uma Cidade Pioneira Paulista: Presidente Prudente. Presidente Prudente: FFCLPP/UNESP, 1972.

CAMARGO, M. J. de Princípios de arquitetura Moderna na obra de Oswaldo Arthur Bratke. 2000. Tese (Doutorado) / Faculdade de Arquitetura e Urbanismo - FAUUSP Universidade de São Paulo, São Paulo.

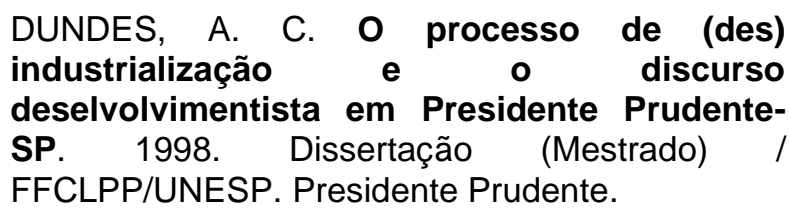

GUADANHIM JUNIOR, S. Influência da arquitetura moderna nas casas de Londrina: 1955-1965. 2002. Tese (Doutorado) / Faculdade de Arquitetura e Urbanismo - FAUUSP Universidade de São Paulo, São Paulo.

HIRAO, H. Arquitetura moderna paulista, imaginário social urbano: uso e apropriação do espaço. 2008. Tese (Doutorado) / UNESP. São Paulo.

LAKATOS, E. M.; MARCONI, M. de A. Metodologia do trabalho científico. São Paulo: Atlas, 1990.

LEITE, J. F. A Alta Sorocabana e o Espaço Polarizado de Presidente Prudente. Presidente Prudente: FFCLPP/UNESP, 1972.

OLIVEIRA, M. L. Presidente Prudente: O Uso do Solo na Área Central. Presidente Prudente: FUNDAP, 1984. (Relatório de Pesquisa). 
SEGAWA, H. Arquiteturas no Brasil. 2.ed. São Paulo: EDUSP, 1999.

SPOSITO, M. E. B.; GUIMARÃES, R. B. (Org). Conjuntura Prudente 97. Presidente Prudente, FCT/UNESP, 1997.

WHITACKER, A. M. A Produção do Espaço Urbano em Presidente Prudente: uma discussão sobre a centralidade urbana.

Presidente Prudente: UNESP, 2008. 